\title{
Repensando a tradição: a variabilidade estilística na arte rupestre do período intermediário de representações no alto-médio rio São Francisco
}

\author{
Loredana Ribeiro *
}

RIBEIRO, L. Repensando a tradição: a variabilidade estilística na arte rupestre do período intermediário de representações no alto-médio rio São Francisco. Revista do Museu de Arqueologia e Etnologia, São Paulo, 17: 127-147, 2007.

Resumo: Este artigo apresenta os principais resultados das análises estilísticocomparativas realizadas em sítios rupestres do norte mineiro e sudoeste baiano: [1] uma periodização hipotética para a arte rupestre regional; [2] a caracterização da distribuição e uso do espaço pelos estilos atribuídos ao período intermediário de ocupação dos suportes; e [3] a caracterização de aspectos gráficos desses estilos, cujo aparecimento e desaparecimento demarcam as rupturas de padrão observadas. Aliada aos resultados da pesquisa empírica, a discussão final sobre a noção de tradição arqueológica reflete sobre as implicações metodológicas desse conceito na arqueologia da arte rupestre.

Palavras-chave: Arte rupestre - Brasil central - Tradição arqueológica Análises estilísticas.

E ste artigo discute a variabilidade estilística na arte rupestre do norte mineiro e sudoeste baiano no período intermediário de representações, a partir de uma centena de sítios arqueológicos estudados entre 2001 e 2006 (Mapa 1). ${ }^{1}$ Os abrigos analisados se distribuem por uma região que cobre cerca de $17.000 \mathrm{~km}^{2}$ no sudoeste da Bahia (municípios de Serra do Ramalho, Coribe, Cocos, Carinhanha e Feira da Mata) e extremo norte de Minas Gerais (Montalvânia, Itacarambi e Januária).

A classificação estilística foi o critério adotado nesta pesquisa para buscar compreen-

(*) Setor de Arqueologia, MHN/UFMG

(loredana.ribeiro@gmail.com)

(1) Projeto de tese de doutoramento desenvolvido no MAE/

USP com financiamento da Fapesp (Ribeiro 2006). der o desenvolvimento das manifestações rupestres nesta região, para identificar novas expressões e para organizar a arte rupestre regional em cronologia relativa, acreditando que uma seqüência estilística detalhada poderia ser melhor cotejada à seqüência arqueológica estratigráfica regional, favorecendo, assim, as correlações entre arte rupestre e demais testemunhos de atividades humanas préhistóricas. Para definir os estilos regionais foram privilegiadas características temporais das figuras (cronologia relativa); de inscrição no espaço (da escolha do suporte à inserção dos abrigos na paisagem, observando os atributos físicos e visuais recorrentes nos suportes, abrigos e áreas onde ocorrem as figuras de cada estilo); e gráficas (temática, morfologia, associações preferenciais, tratamento técnico etc.), buscando focar a análise igualmente 
Repensando a tradição: a variabilidade estilística na arte rupestre do período intermediário de representações no alto-médio rio São Francisco. Revista do Museu de Arqueologia e Etnologia, São Paulo, 17: 127-147, 2007.

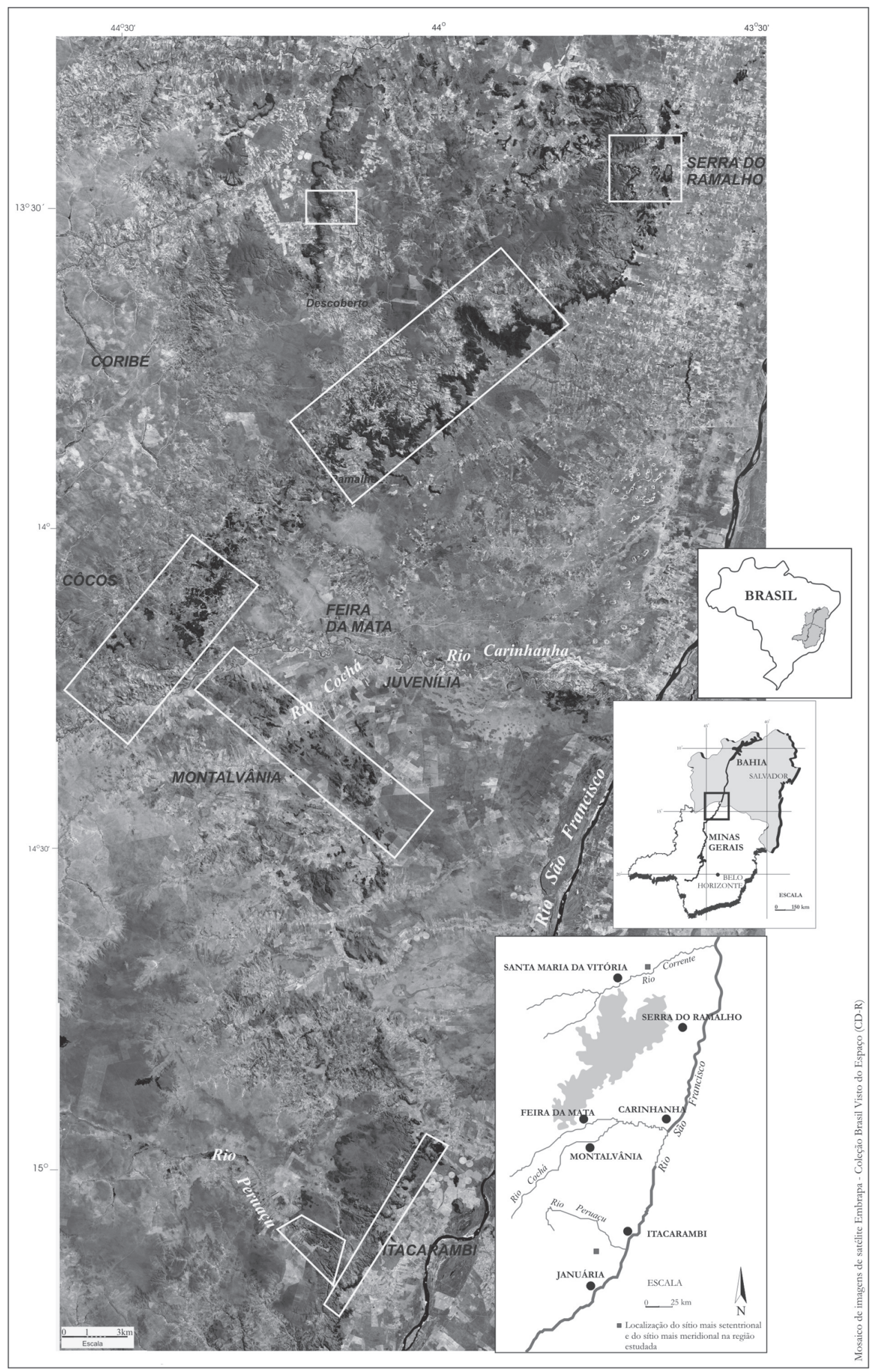

Mapa 1. Localização da região da pesquisa e delimitação aproximada das concentrações de sítios estudados. 
em todos estes aspectos da arte rupestre e não apenas em seus marcadores gráficos.

A pesquisa teve como ponto de partida os repertórios temáticos caracterizados nas tradições rupestres descritas nos últimos vinte anos que podem ser encontrados na região em estudo: tradições Agreste, Nordeste, São Francisco e Complexo Montalvânia (Guidon 1981; Isnardis 2004; Martin 1997; Pessis 1989, 2003; Pessis e Guidon 2000; Prous 1989; Ribeiro e Isnardis 1996-97; Silva e Ribeiro 1996; Schmitz e outros 1997, entre outros). As manifestações regionais de cada um desses padrões gráficos foram inicialmente agrupadas em momentos (ou níveis) crono-estilísticos de realização, definidos pela cronologia relativa e aspectos gráficos das figuras. Posteriormente, os momentos pertencentes a cada repertório temático foram comparados entre si, em busca de elementos (gráfico-temáticos, cronológicos e espaciais) que confirmassem sua classificação independente ou que articulassem mais de um momento de realização de figuras na composição de um estilo (para descrições detalhadas dos estilos identificados, ver Ribeiro 2006: 164 229). Assim, dos doze estilos regionais definidos nesta pesquisa, três deles foram atribuídos pela temática à Tradição Agreste, três à Tradição São Francisco, dois ao Complexo Montalvânia e um à Tradição Nordeste, enquanto três outros não foram atribuídos a nenhum dos repertórios gráficos descritos.

A análise regional buscou então comparar entre si as características dos estilos identificados em três dimensões: no tempo, no espaço e em seus marcadores gráficos. Possíveis afiliações culturais podem ser melhor discutidas com a observação de relações significativas entre estilos em mais de uma destas dimensões do que a partir de relações observadas em apenas uma delas - seja, por exemplo, a temporal ou a gráfico-temática, a mais utilizada. ${ }^{2}$ A observação de padrões envolvendo os

(2) Análise inspirada na proposta de Hodder (1986) e Hodder e Hutson (2003) de organizar e inquirir o registro arqueológico a partir de quatro dimensões da variação, correspondentes ao tempo, ao espaço, à unidade deposicional e à tipologia, para favorecer a elaboração de um contexto arqueológico mais amplo. mesmos estilos nas três categorias de variação pode favorecer a elaboração de periodizações hipotéticas da arte rupestre regional, associando-a aos demais itens do registro arqueológico.

Adiante se apresenta a seqüência cronológico-estilística disponibilizada pelos trabalhos contínuos da equipe do Setor de Arqueologia com a arte rupestre do norte mineiro, apontando-se os limites observados nessa organização e a necessidade de mudanças na orientação das pesquisas para obtenção de resultados mais abrangentes. Posteriormente é discutida uma periodização hipotética elaborada para a arte rupestre regional (Ribeiro 2006), na qual as informações cronológicas disponíveis (datações absolutas e relativas, superposições e pátinas) são utilizadas para inserir os estilos rupestres intermediários na seqüência regional de ocupação humana pré-histórica e balizar cronologicamente os padrões observados nas formas de utilização do espaço e na variação gráfica dessa arte rupestre. A partir de então, as discussões são focadas em características da distribuição e uso do espaço e em aspectos gráficos das manifestações rupestres do período intermediário, cujo aparecimento e desaparecimento demarcam as rupturas de padrão observadas.

A discussão desenvolvida aqui sugere que seria mais proveitoso deixarmos temporariamente de lado as amplas categorizações culturais e buscarmos antes compreender o registro rupestre das ocupações pré-históricas em suas particularidades temporais e espaciais, para depois observar como suas especificidades se alinham. Juntamente com os resultados da pesquisa empírica, a discussão final sobre a noção de tradição arqueológica pretende refletir sobre as implicações metodológicas do uso desse conceito na arqueologia da arte rupestre, implicações que independem de conhecermos ou aplicarmos voluntariamente as noções de cultura subjacentes.

\section{A arte rupestre regional no Holoceno médio: seqüências estilístico-sucessória e estratigráfica dos abrigos}

A região norte de Minas Gerais e o sudoeste da Bahia tem sido alvo de estudos 
Repensando a tradição: a variabilidade estilística na arte rupestre do período intermediário de representações no alto-médio rio São Francisco. Revista do Museu de Arqueologia e Etnologia, São Paulo, 17: 127-147, 2007.

arqueológicos de equipes da UFMG, da UNISINOS, da UCG e do IAB, desde os anos de 1970. Ao passo que a ocupação humana regional recebia datações muito recuadas (cerca de 12-11.000 AP) já na primeira década de escavações, um rico e diversificado registro rupestre foi desde então identificado e classificado em tradições e unidades estilísticas (Prous 1996-97; Prous e outros, 1980, 1984; Ribeiro 1996-97; Schmitz e outros 1984 e 1997; Seda 2003; Silva 2002; por exemplo).

Como na maior parte das pesquisas disponíveis sobre arte rupestre brasileira, estes estudos foram norteados pela organização e classificação temática, definindo tradições rupestres (a unidade classificatória maior) e completando essas caracterizações através da identificação de sub-tradições, estilos ou fácies (categorias menores, geralmente componentes de uma tradição). De modo geral, as tradições rupestres foram definidas a partir da repetição de traços temáticos - o que indicaria continuidade cultural e corresponderia a códigos ou repertórios partilhados por grupos separados no espaço, no tempo ou em ambos (Calderón 1970; Martin 1997; Pessis e Guidon 2000; Prous 1999a). A variação interna às tradições, as sub-tradições, estilos ou fácies, normalmente apresenta diferenças sutis de definição, e tem sido descrita principalmente através dos tratamentos gráficos (morfologias e técnicas) e supressões/ampliações na representação dos temas tradicionais, tal como ocorrem no tempo (cronologia relativa) e/ou no espaço (distribuição geográfica).

Destas equipes que atuam ou atuaram na região norte mineira e sudoeste baiana, a do Setor de Arqueologia da UFMG foi uma das que mais se envolveu com a caracterização e organização de seqüências estilístico-sucessórias regionais (Isnardis 2004; Prous 1989, 1992; Ribeiro e Isnardis 1996-97; Ribeiro 2003; Silva e Ribeiro 1996, entre outros). De acordo com esses trabalhos, a seqüência das tradições rupestres identificadas no norte de Minas Gerais pode ser esquematizada no Quadro 1 e brevemente descrita conforme segue.

As figuras pioneiras crresponderiam a uma expressão regional da Tradição Agreste, com antropomorfos realistas e grafismos geométricos, pouco freqüentes nos abrigos e em poucas figuras por sítio, definindo o período antigo de representações rupestres. Sobre elas encontraríamos figuras geométricas, de armas e outros temas da Tradição São Francisco, descritos em vários estilos, além de pinturas e gravuras de seres antropomorfos, geométricos, armas e pés do Complexo Montalvânia. Não é clara a ordem de sucessão entre os conjuntos de grafismos São Francisco e Montalvânia, devido à raridade de superposições e aos sinais de alternância entre estilos desses repertórios temáticos distintos, mas alguns pesquisadores acreditam que as vistosas figuras São Francisco possam ter começado a ser pintadas antes das figuras Montalvânia e que estas últimas apareçam de modo intrusivo em painéis sanfranciscanos (Isnardis 2004; Prous 1996-97). De todo modo, ambos os repertórios são inseridos no período intermediário da arte rupestre regional. Posteriormente, na transição para o período recente de expressões rupestres, aparecem novos grafismos de seres vivos (principalmente zoomorfos, antropomorfos e vegetais cultivados), passiveis de serem atribuídos à Tradição Agreste pela temática realista e o característico detalhamento anatômico dos seres vivos, pintados sobre os estilos sanfranciscanos e Montalvânia. Sobre as figuras de seres vivos realistas, manifestações regionais da Tradição Nordeste, além de uma sucessão de grafismos não atribuídos ou de ocorrência apenas local, vários deles com representações de cultígenos, ocupam os suportes rochosos do norte de Minas Gerais.

Essa seqüência sugeria que três grupos culturais, representados graficamente pelas tradições Agreste, São Francisco e Montalvânia, seriam os responsáveis pelo registro rupestre anterior à introdução das representações realistas de vegetais cultivados na região. Essa sucessão cultural poderia ter se dado entre 12.000 AP (data das primeiras ocupações humanas conhecidas) e 3-2.000 AP (período que corresponde a uma datação disponível para figura recente de uma dessas tradições São Francisco - e à presença de vestígios inquestionáveis de agricultura nas camadas arqueológicas). 


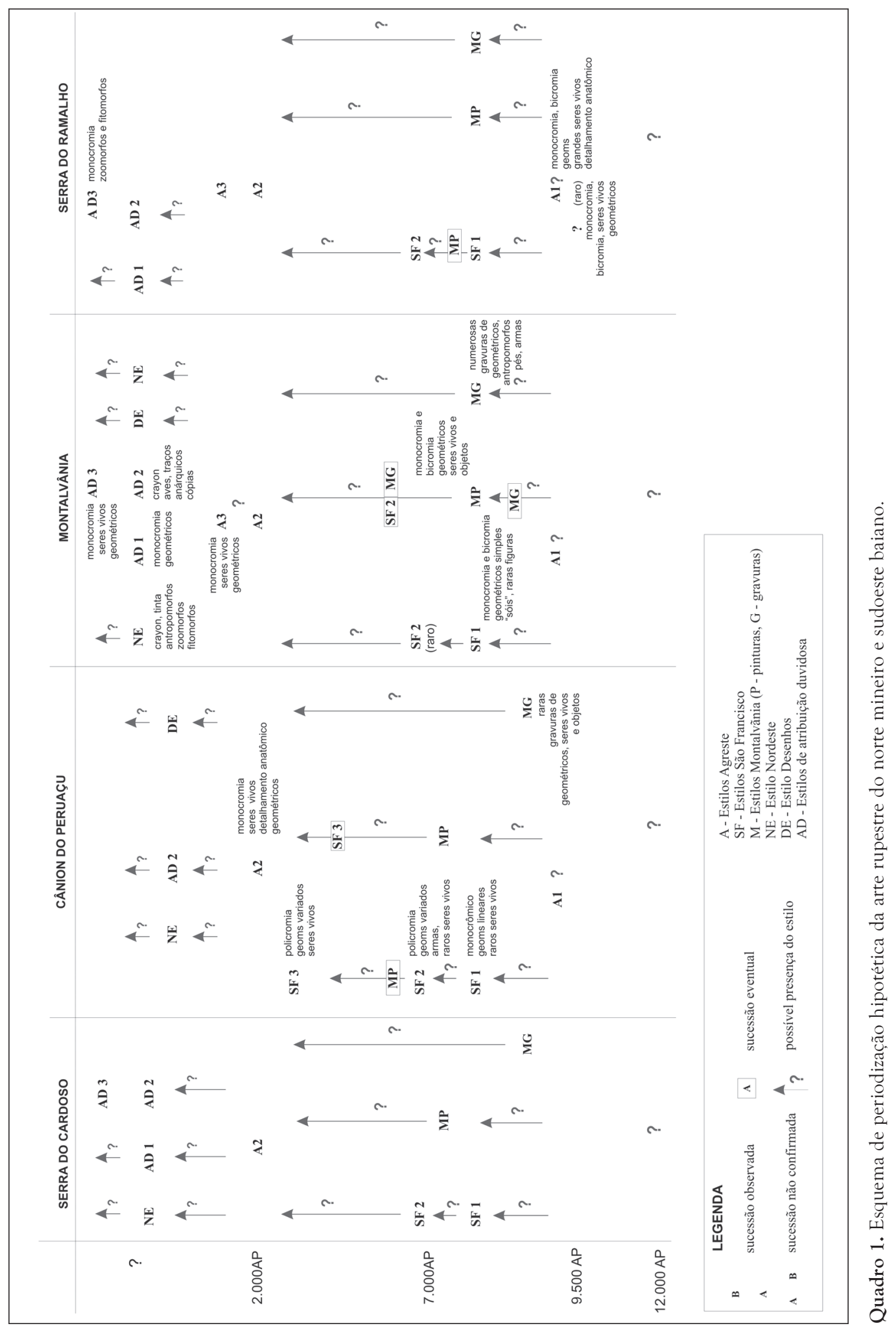


Repensando a tradição: a variabilidade estilística na arte rupestre do período intermediário de representações no alto-médio rio São Francisco. Revista do Museu de Arqueologia e Etnologia, São Paulo, 17: 127-147, 2007.

A partir destes três padrões temáticos da arte rupestre, propõe-se agora discutir as relações entre esta seqüência estilístico-cultural e os padrões tecnológicos observados no registro arqueológico das camadas estratigráficas dos abrigos nesse intervalo de quase dez mil anos.

A estratigrafia dos abrigos do norte mineiro mostra a predominância de um padrão tecnológico lítico inicial, associado à Tradição Itaparica, que é bruscamente substituído em 9.500 AP. O outro padrão lítico que começa a ser encontrado em camadas arqueológicas do norte de Minas Gerais e do sudoeste da Bahia dessa época é acompanhado, no Peruaçu, pelos primeiros vestígios datados de arte rupestre na região, em 9-7.000 AP, e de sepultamentos nos abrigos ao menos desde cerca de 7.000 AP (Fogaça 2001; Prous 199697; Prous e Schlobach 1997; Rodet 2006; Schmitz e outros 1989). A datação relativa para a arte rupestre regional indica que entre 9. 7.000 AP um bloco se desprendeu do teto da Lapa do Boquete, foi coberto por incisões, depois por gravuras, depois por cupules, e finalmente quase totalmente soterrado (Prous 1999b).

Ainda que a datação do bloco enterrado esteja no intervalo definido pelas evidências seguras de arte rupestre mais antiga no Brasil (Pessis 1999; Prous 1999b), ela não permite afirmar que essa atividade apenas tenha tido início nesse período de 9-7.000 AP. É possível que a arte rupestre já fosse anteriormente praticada, todavia de modo pouco intensivo, deixando assim vestígios arqueologicamente menos visíveis. As mudanças no padrão tecnológico lítico e o novo uso (ou intensificação no uso) de abrigos rochosos para sepultar os mortos podem ter sido acompanhados não pela introdução da arte rupestre, mas por um investimento nessa atividade suficientemente maior que em épocas anteriores para deixar indicadores arqueológicos mais visíveis.

As manifestações Agreste pioneiras, caracterizada por poucas figuras (às vezes uma ou duas), sem superposições ou diferença de pátina e presentes em poucos sítios, evocam uma prática esporádica da arte rupestre (já sugerido por Isnardis 2004), que deixaria vestígios arqueológicos menos numerosos e talvez arqueologicamente menos visíveis. Mas a raridade de informações para estas ocorrências gráficas mais antigas impede maiores avanços na análise, elas tanto podem ter sido pintadas por grupos pós-lascadores Itaparica que ocuparam a região, quanto por grupos contemporâneos a essa indústria lítica, não há ainda como atribuir.

Já para os estilos posteriores às figuras Agreste, atribuídos à Tradição São Francisco e ao Complexo Montalvânia, existem informações mais numerosas, tanto cronológicas, quanto espaciais e gráficas, que permitem inferências hipotéticas de contextualização dessa arte rupestre no restante do registro arqueológico.

As gravuras do bloco enterrado são redes, anéis concêntricos, linhas sinuosas e biomorfos, que aparecem às centenas em painéis expostos de gravuras e pinturas do Complexo Montalvânia (Ribeiro 2006). As superposições entre essas gravuras e pinturas são raríssimas (cada qual ocupa um suporte específico, como se verá adiante) e dentre os poucos casos conhecidos há tanto gravuras muito erodidas subpostas a vestígios de pinturas, quanto gravuras que se superpõem a pinturas. Na seqüência da arte rupestre, além do Complexo Montalvânia, o outro conjunto mais recente que as pinturas Agreste é a Tradição São Francisco. Tal como acontece entre as gravuras e pinturas Montalvânia, não há segurança na ordem sucessória entre os estilos sanfranciscanos e Montalvânia. Geralmente, as pinturas São Francisco e Montalvânia ou não se superpõem entre si ou o fazem em alternância. Fortes distinções de pátinas em figuras de um mesmo painel de gravuras ou pinturas Montalvânia e a presença de três estilos sanfranciscanos que se superpõem entre si, sugerem que as execuções dos grafismos dos dois repertórios temáticos se deram ao longo de muito tempo. Tanto nos estilos São Francisco quanto naqueles Montalvânia, há evidências de que essas representações continuaram a 
ser realizadas até o período agricultor. ${ }^{3}$ Uma datação direta por AMS do pigmento de um grafismo atribuído aos estilos sanfranciscanos intermediário ou recente resultou na idade $2.680 \pm 180$ AP (Russ e outros 1990), e pinturas que sugerem cultígenos aparecem entre os grafismos menos patinados de um e outro repertório.

Ambos os conjuntos gráficos mostram grande investimento na prática de arte rupestre. Nos estilos São Francisco, esse investimento é evidenciado na sua variação estilística e no tratamento visual dado aos painéis, por vezes muito altos, repletos de figuras grandes, coloridas e elaboradas. Nos estilos Montalvânia, o investimento está no uso intenso de painéis e abrigos. São essas figuras que ocupam o maior número de sítios dentre os aproximadamente 150 estudados em trabalhos recentes na região: são 125 abrigos com figuras Montalvânia, contra cerca de 60 abrigos com ocorrências sanfranciscanas (Isnardis 2004, tabelas 1 e 2; Ribeiro 2006, anexo 1). São também essas figuras que se apresentam em painéis que mostram um horror vacui em sua composição, onde, virtualmente, todo o suporte é ocupado, por vezes com milhares de figuras.

Em resumo, existem elementos cronológicos diretos e indiretos que permitem uma atribuição hipotética dos estilos sanfranciscanos e Montalvânia ao intervalo entre 9-7.000 e 32.000 AP, sem que haja elementos conclusivos para ordenar sucessoriamente estes dois repertórios temáticos entre si. Nos abrigos regionais, as camadas arqueológicas dessa época costumam ser perturbadas por fossas posteriores (sepultamentos, "silos", "postes"), mas o registro arqueológico de sedimentos intactos de alguns sítios sugere continuidade ao longo de boa parte deste período para vários autores (Prous 1996-97; Prous e outros 1996-97; Schmitz e outros 1996; Rodet 2006, etc.). Do mesmo modo, as análises gráficas e

(3) Os vestígios inquestionáveis de agricultura na região são datados de cerca de $2.000 \mathrm{AP}$, mas a idade estimada para o início do cultivo de vegetais na região do Peruaçu é 4.000 AP, a partir de negativos de fossas de "silos" (Prous 1996-97). espaciais sugerem continuidade e conectividade entre dois repertórios, sugerindo que as descrições anteriores da Tradição São Francisco e do Complexo Montalvânia possam estar separando manifestações aparentadas, no lugar de caracterizar comunidades culturais distintas.

Questões como essa sugerem que uma flexibilização dos critérios de classificação, adaptando-os às contingências contextuais da arte rupestre em estudo, permite explorar melhor o potencial informativo da arte rupestre. Perspectivas que abordam a arte rupestre como manifestação ou reflexo de regras culturais podem ser questionadas em favor da afirmação do estilo como produção, atuação e manipulação de orientações e modulações culturais, onde repertórios temáticos tradicionais podem ser criados, combinados e modificados. Isso permite expandir os critérios classificatórios, desvinculando a análise da arte rupestre de rígidos padrões temáticos pré-determinados. Pensar que os estilos São Francisco e os estilos Montalvânia se relacionavam a distintas comunidades de autores embotava o estudo das associações e dos diálogos observados entre estas representações, restringindo a explicação a contatos indiretos entre os autores dos estilos, através de figuras preexistentes nos abrigos ocupados. Também reduzia a visibilidade de oposições sutis em diversos aspectos do comportamento destes estilos, da seleção temática à distribuição espacial, como se discute adiante.

\section{A domesticação do meio ambiente: paisa- gens complexas São Francisco e Montalvânia}

Cerca de $200 \mathrm{~km}$ separam o sítio mais setentrional na região da pesquisa daquele mais meridional. As áreas entre eles são compostas por um diversificado contexto físico, no qual são conhecidas atualmente mais de duas centenas de sítios com arte rupestre (Ribeiro 2006). Estes sítios se distribuem por áreas com paisagens naturais muito distintas, especialmente no que diz respeito a seus relevos calcários e recursos hídricos. Existem marcadas diferenças no grau de evolução cárstica local e os recursos 
Repensando a tradição: a variabilidade estilística na arte rupestre do período intermediário de representações no alto-médio rio São Francisco. Revista do Museu de Arqueologia e Etnologia, São Paulo, 17: 127-147, 2007.

hídricos se distribuem regionalmente em variados níveis de abundância e acessibilidade (Bitencourt e Rodet 2002; Baggio Filho 1991; Rodet e outros 2005) e as áreas em estudo apresentam um mosaico de formações vegetais pertencentes aos domínios do cerrado e da caatinga. A diversificada configuração bio-física da região permite estudar sítios arqueológicos rupestres de variada inserção na topografia local e regional, com diferentes tamanhos e morfologias e implantados em cenários naturais que podem ser bastante distintos de uma área a outra. Os grupos de praticantes da arte rupestre São Francisco e Montalvânia domesticaram estes cenários naturais de modo radical e exclusivo no contexto rupestre do norte mineiro e sudoeste baiano.

A geomorfologia das áreas em estudo pode ser descrita desde aquela que apresenta um carste menos evoluído (Peruaçu) até a que apresenta relevo cárstico mais residual (Montalvânia), com a Serra do Ramalho ocupando uma posição intermediária entre estes dois extremos regionais de evolução cárstica. O Peruaçu oferece paisagens fechadas (a largura do cânion principal não ultrapassa $150 \mathrm{~m}$ ), com horizonte dominado por altas escarpas e suntuosas entradas de cavernas. Montalvânia, pelo contrário, pode ser descrita por seus belos cenários descobertos, com campos de lapiás a perder de vista, abrigos e cavernas magníficos, porém abertos em escarpas que não nos fazem tombar a cabeça para trás para serem admiradas. Na Serra do Ramalho as formas cársticas são modestas, ainda que grandiosas e exuberantes cavernas com rios subterrâneos guardem mistérios de padres e aventureiros que nelas entraram e nunca mais saíram - são paisagens entremeadas de espaços abertos e fechados.

Como a colonização humana na região é posterior à formação desses relevos, pode-se considerar que as populações pré-históricas depararam com paisagens cársticas similares às que atualmente nos encantam a vista. Diferentes contextos hídricos e florísticos também podem (e podiam) ser encontrados na região, configurando, por um lado, fontes alternativas e relativamente próximas de recursos alimenta- res e, por outro, delimitando fluidamente cada uma das áreas através de características ambientais particulares.

A primeira evidência da importante transformação do meio cárstico regional promovida pela arte rupestre dos estilos São Francisco (SF) e Montalvânia (M) está na quantidade de abrigos utilizados para pintar ou gravar as figuras desses estilos, especialmente as pinturas Montalvânia, e em sua dispersão espacial (Prancha 1). São 130 abrigos ocupados por figuras dos cinco estilos atribuídos a estes repertórios temáticos, dentre os cerca de 150 estudados em pesquisas sistemáticas dos últimos anos (Isnardis 2004; Ribeiro 2006; Ribeiro e Isnardis 1996/97; Silva e Ribeiro 1996), número ainda sem par em outros períodos da seqüência estilístico-sucessória regional. Enquanto os abrigos com figuras Montalvânia se distribuem de norte a sul na região (inclusive aparecendo nos sítios mais setentrional e mais meridional indicados no Mapa 1), os abrigos ocupados por figuras sanfranciscanas se concentram em áreas com características específicas no carste regional (Prancha 1).

Cada estilo tem suporte ou suportes preferenciais, que muitas vezes foram desprezados ou timidamente ocupados pelos outros (Prancha 2). As pinturas de todos os estilos São Francisco estão principalmente em painéis altos e destacados; as pinturas Montalvânia estão geralmente em painéis discretos, colocados sobre superfícies de média altura, irregulares e compartimentadas; as gravuras aparecem nos suportes naturalmente polidos que estão em pisos nas zonas de penumbra dos abrigos ou nas bases de paredes. As diferenças de suporte preferencial são tão marcadas que, excluindo as seqüências sanfranciscanas em alguns sítios do Peruaçu (por exemplo estilos SF1, SF2 e SF3 bem representados na Lapa do Rezar) não se conhece ainda nenhum painel que tenha sido igualmente utilizado por dois ou três destes estilos combinados (MG, MP, SF1, SF2 e SF3). Na Lapa do Gigante (Montalvânia), essa compartimentalização preferencial dos suportes foi evidenciada graficamente através de linhas paralelas pinta- 

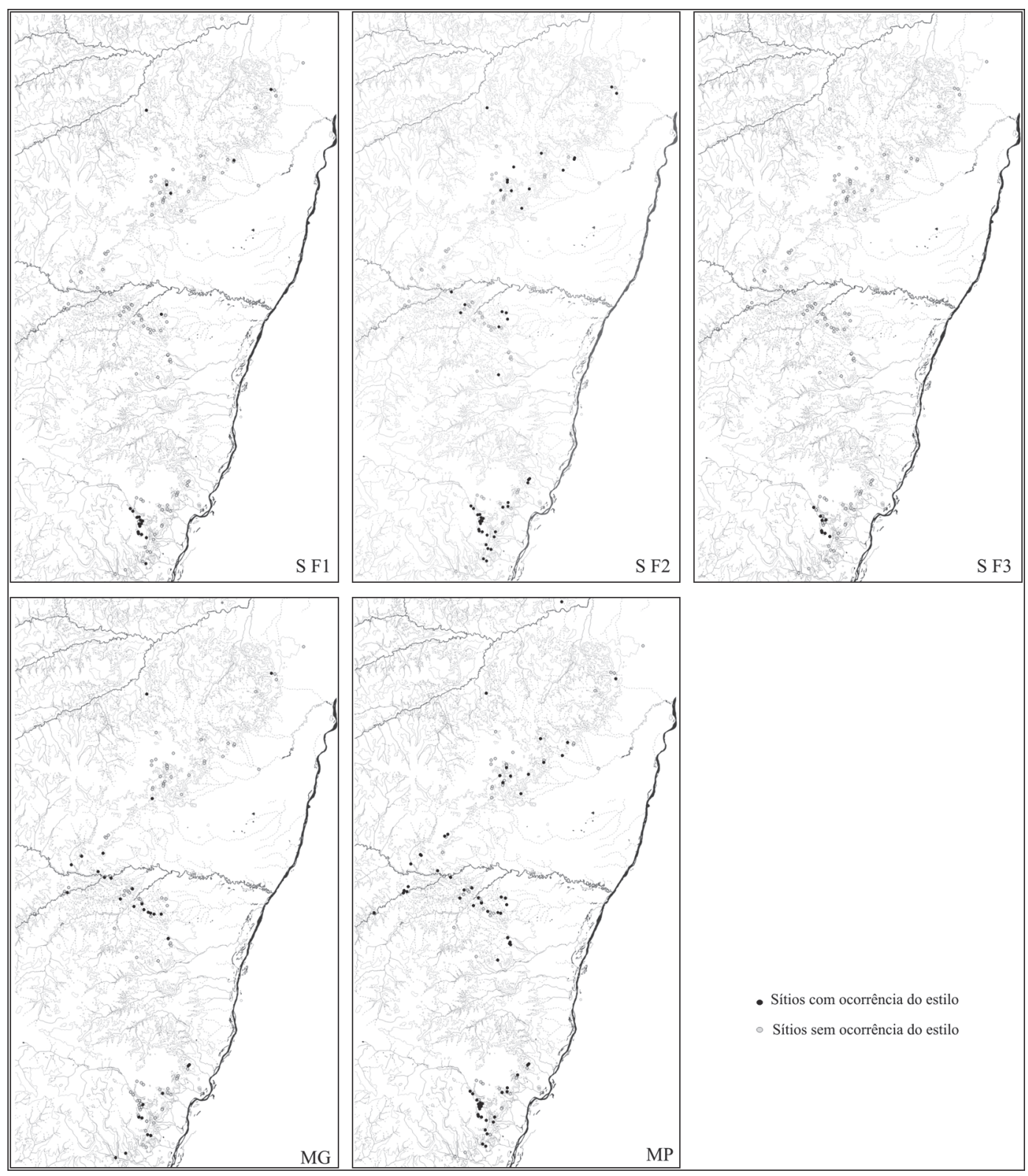

- Sítios com ocorrência do estilo

- Sítios sem ocorrência do estilo

Prancha 1. Distribuição espacial dos estilos São Francisco e Montalvânia.

das, acompanhadas por pontos gravados. As gravuras são encontradas na parte inferior dos suportes, abaixo das linhas, enquanto acima delas estão as pinturas sanfranciscanas, raras figuras Montalvânia, e grafismos mais numerosos de outros estilos (Ribeiro 1996-97).

De modo geral, as alturas médias dos suportes preferenciais e a maior ou menor exposição dos painéis distinguem estes estilos entre si conforme apresentado na Tabela 1.

Um padrão marcante, no que diz respeito aos sítios densamente utilizados pelos estilos São Francisco é a ausência de representações igualmente numerosas dos estilos Montalvânia e vice-versa. $\mathrm{O}$ mesmo vale para a ocupação mais intensa dos abrigos para receber 


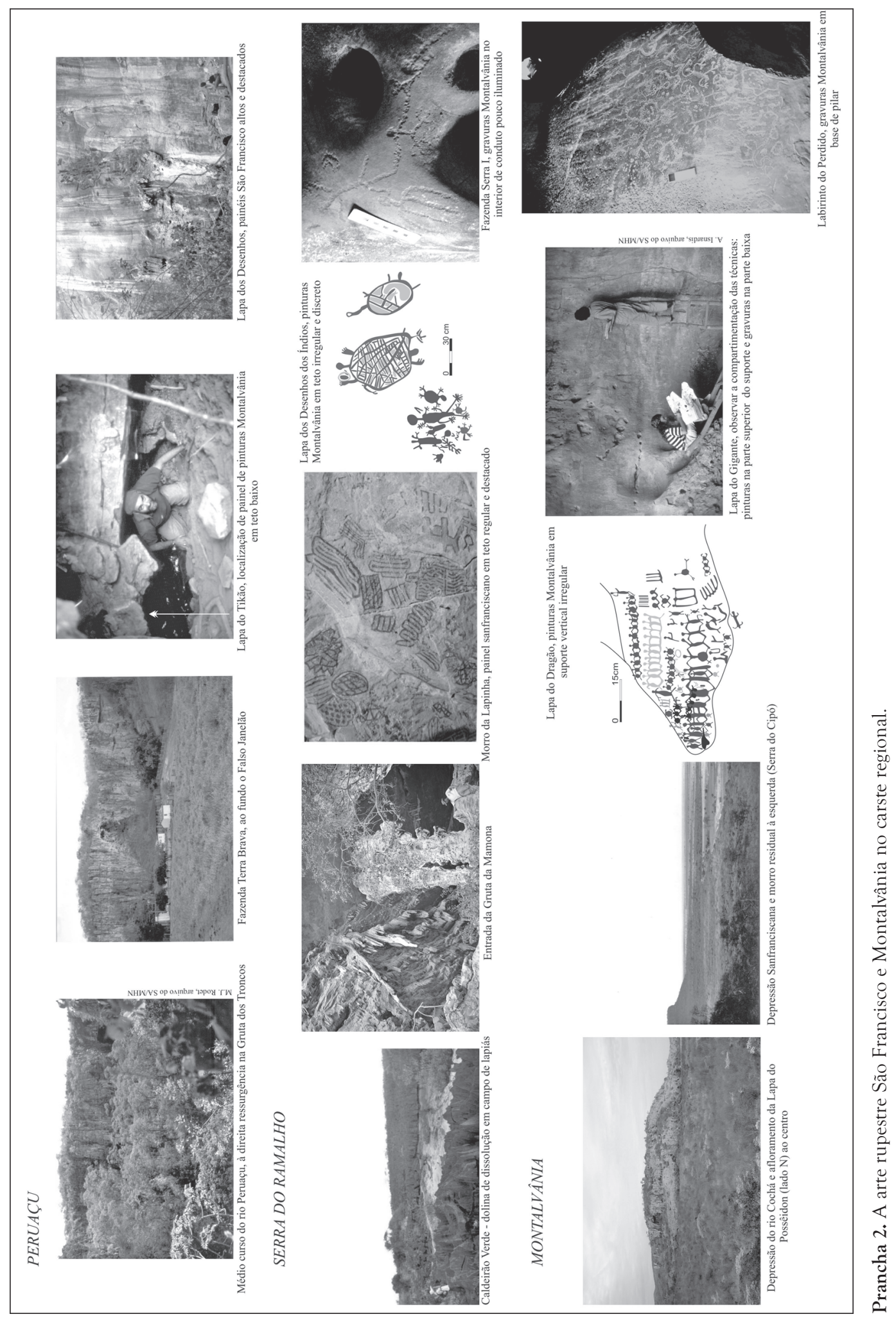


Tabela 1

\begin{tabular}{lcc}
\hline Estilos & Altura relativa dos painéis & Exposição relativa dos painéis \\
\hline São Francisco (SF1, SF2 e SF3) & altos ou médio-altos & Muito visíveis \\
Montalvânia em pinturas (MP) & $\begin{array}{c}\text { médios e médios-baixos } \\
\text { (tetos escalonados) }\end{array}$ & discretos ou muito discretos \\
Montalvânia em gravuras (MG) & baixos (piso) ou & discretos (zonas de penumbra) \\
\hline
\end{tabular}

grafismos dos estilos Montalvânia em pintura e gravura: onde há um não costuma haver o outro. Por outro lado, em todas as áreas da pesquisa podem ser encontrados abrigos onde painéis com figuras Montalvânia ou São Francisco foram reutilizados por estilos posteriores. Não se observam, no comportamento dos estilos recentes, padrões de ausência ou baixa freqüência de figuras dos estilos sanfranciscanos ou Montalvânia nos abrigos escolhidos (Ribeiro 2006: 269-299).

Ao contrário dos suportes escolhidos, as características físicas dos abrigos regionais que comportam cada uma das manifestações sanfranciscanas e Montalvânia variam bastante (por exemplo, tamanho da área abrigada, posição nas vertentes, tipo de piso e proximidade com a água). Os atributos físicos dos abrigos rochosos não permitem estabelecer grandes associações entre abrigos e estilos, seja por atração ou rejeição. Mas características dos painéis de arte rupestre e das paisagens naturais onde se encontram os abrigos utilizados permitem-no, levando a crer que o uso dos abrigos para pintar ou gravar pudesse ser guiado mais por uma identificação entre representação rupestre, suporte rochoso e meio circundante do que propriamente por características dos abrigos rochosos. Tão importante quanto as diferenças entre os painéis desses estilos (localização, altura e exposição dos painéis e certa exclusividade, nos painéis e nos abrigos, de um estilo em relação aos outros) é o contraste que se define entre esses painéis e as paisagens naturais nas quais se inserem os abrigos escolhidos.

Os painéis Montalvânia em gravura e pintura são encontrados em zonas de certo modo subterrâneas no interior dos sítios: são pisos no fundo dos abrigos, tetos baixos e escalonados, reentrâncias das paredes, pequenas cavidades nos maciços rochosos. Muitos dos locais que receberam estas figuras parecem sinalizar pontos de captação sazonal ou subterrânea de água (abrigos com reservatórios naturais, zonas de forte gotejamento, sítios nas bases de encostas onde correm águas temporárias; além de sítios vizinhos a fendas verticais que interceptam o lençol freático e em entradas de cavernas com acesso ao lençol ou com ponto de ressurgência hídrica). Os painéis Montalvânia parecem ser mais numerosos onde as paisagens cársticas são mais evoluídas e pobres em exuberantes paisagens subterrâneas, como as áreas de relevos abertos e dissecados de Montalvânia e setores sudoeste e nordeste da Serra do Ramalho. Esta arte rupestre se associa às zonas mais profundas dos abrigos rochosos ou visualmente menos acessiveis, conjugando painéis geralmente discretos ou pouco evidentes a relevos abertos e formas cársticas superficiais muito evidentes. Se vemos a arte rupestre como forma de apropriação do espaço, a prática do estilo Montalvânia em gravuras talvez possa ser relativa a um contexto muito particular de ritualização das conexões entre os grupos humanos locais e as paisagens subterrâneas: com esse estilo, as figuras não são colocadas sobre a rocha (tinta sobre o suporte), mas retiradas da rocha dos fundos dos abrigos ou na base das paredes - uma figura gravada é o resultado de pontos de rocha retirados no suporte.

Já os painéis sanfranciscanos são destacados nos abrigos, geralmente em suportes altos e bem visíveis, e são mais numerosos em áreas de exuberantes formações subterrâneas, onde muitas vezes estão nas entradas de grutas. Os 
Repensando a tradição: a variabilidade estilística na arte rupestre do período intermediário de representações no alto-médio rio São Francisco. Revista do Museu de Arqueologia e Etnologia, São Paulo, 17: 127-147, 2007.

sítios sanfranciscanos estão em posições topográficas elevadas (Montalvânia) ou em áreas com relevos fechados e imponentes (como os cânions do Peruaçu e do Morro Furado, além do setor sudeste da Serra do Ramalho). Também é possível ver uma associação entre os locais onde estão os painéis sanfranciscanos e a disponibilidade de água permanente em superfície. Assim é que a maioria dos sítios está em cânions ainda ativos ou desativados nas últimas décadas (Peruaçu, Minará, Morro Furado, Boqueirão, Bomfim etc.). Esta arte rupestre que salta à vista está associada justamente a ambientes cujas formações rochosas precisam ser descobertas aos poucos, na medida em que se caminha entre altas vertentes de cânions ou se atravessa cavernas profundas, escuras ou pouco iluminadas.

As inversões entre as características visuais dos estilos, dos suportes escolhidos e das paisagens onde se inserem os abrigos sugerem que os contrastes e as similaridades entre os estilos Montalvânia e São Francisco possam fazer parte, de modo complementar, de uma mesma apropriação e transformação do meio ambiente. Paisagens culturais são construídas através das relações entre pessoas e o espaço, autores como Ingold (1995, 2000); Hodder (1999); Hodder e Hutson (2003) e outros têm defendido que o espaço é qualitativamente experienciado, e que nossas visões de mundo são criadas no engajamento prático e cotidiano com o meio circundante. A atuação da arte rupestre Montalvânia e São Francisco na construção da paisagem talvez incluísse realizações gráficas com atributos opostos a algumas características naturais do meio cárstico. Eventualmente, essa oposição podia estar relacionada a uma inversão simbólica que favorecesse a apropriação humana e socialização do meio ambiente rochoso.

Tomando em conjunto as distribuições espaciais dos estilos sanfranciscanos e Montalvânia nesta região, observa-se um padrão de uso e transformação do espaço radicalmente diferente daquele definido pelas expressões rupestres pioneiras. Os abrigos onde estes estilos intermediários ocorrem são muito mais numerosos e seus painéis costumam ser densamente ocupados por pinturas ou gravuras, ao contrário do padrão anterior, caracterizado por poucas figuras em poucos sítios. Esse padrão também não ocorre nos períodos posteriores da seqüência estilística regional, onde as expressões tendem a aparecer em áreas geográficas bem menores e nunca em tão numerosos abrigos ou figuras (Ribeiro 2006: 269-299).

As diferenças nos graus de pátina das figuras Montalvânia em gravura e pintura, assim como as superposições entre os estilos sanfranciscanos, são evidências de grande intervalo cronológico englobando este conjunto de representações. Esses elementos indicam também o uso repetido dos mesmos locais para pintar e gravar, na maioria das vezes em relativo respeito preservacionista às ocorrências pré-existentes. A possibilidade do desenvolvimento de diferentes estilos de arte rupestre associados a setores/características especiais da paisagem, bem como sua manipulação por longo tempo, evoca um alto investimento na prática da arte rupestre que por sua vez pode ser indício de grande importância sóciocultural desta atividade. A paisagem construída por estes estilos é fortemente domesticada e pode ter sido configurada num contexto temporal amplo e de maior fixação regional de grupos humanos.

\section{Diálogos internos: as similaridades e os contrastes entre os estilos São Francisco e Montalvânia}

Assim como a observação das relações espaciais entre os estilos São Francisco e Montalvânia, a discussão de suas relações gráficas sugere que estes dois repertórios temáticos podem ser melhor compreendidos se analisados como complementares.

Uma relativa liberdade de trânsito entre as orientações estilísticas Montalvânia e São Francisco pode ser observada em painéis de diversos abrigos da região e algumas vezes torna difícil a atribuição das figuras. Freqüentemente, as formas geométricas que participam das associações temáticas Montalvânia são simila- 
res a formas atribuídas à Tradição São Francisco (Jácome e Ribeiro 2001; Ribeiro 2006: 241257). Nas pinturas, onde as associações se dão particularmente com formas angulares, as figuras mais geométricas que participam das transformações são "redes”, "pentes”, "grades”, ziguezagues e losangos encadeados, figuras muito comuns nos painéis sanfranciscanos, onde entretanto são mais elaboradas, maiores e em policromia.

As comuns "cirandas" de antropomorfos esquemáticos Montalvânia são composições onde se repetem elementos geométricos mínimos (anéis, bastonetes, losangos...) articulados por algum detalhe anatômico (braços, pernas, cabeça, dedos). A repetição de elementos geométricos mínimos é o princípio geral de composição das figuras sanfranciscanas iniciais (SF1) e a combinação de diferentes formas geométricas elementares é recorrente nas figuras do estilo posterior (Prancha 3). Elementos comuns aparecem de modo assistemático nos estilos sanfranciscanos SF1 e SF2 e nas pinturas e gravuras Montalvânia, mas são as figuras sanfranciscanas mais recentes (SF3), de ocorrência restrita ao cânion do Peruaçu, que apresentam de modo muito mais contundente elementos característicos de ambos os conjuntos (Ribeiro 2006: 252-257).

As análises comparativas entre os estilos Montalvânia e São Francisco (detalhadas em Ribeiro 2006: 241-268, 2007) permitiram observar uma especialização temático-estilística própria a cada um dos repertórios temáticos, com os estilos sanfranciscanos primando pelas belas e elaboradas figuras geométricas bicrômicas e policrômicas, enquanto as figuras Montalvânia são principalmente relativas a figuras geométricas simples, seres antropomorfos com maior ou menor esquematismo e objetos. Ao mesmo tempo, temas (como as cirandas ou as armas, por exemplo), tratamento gráfico (monocromia, bicromia, uso de pincéis ou dedo, técnicas de preenchimento etc.) associações temáticas (como antropomorfos e armas, antropomorfos e figuras losangulares) e trocadilhos gráficos (geometrização da figura antropomorfa ou viceversa) similares podem aparecer em painéis de todos estes estilos (Prancha 3). A conexão entre as duas tendências estilísticas é dada principalmente pelos elementos geométricos mínimos (triângulos, losangos, anéis...), congregados na composição das figuras São Francisco e desagregados nas composições esquemáticas Montalvânia em pintura e gravura. Chamei estas relações estilísticas de diálogos internos porque - avaliando juntamente as semelhanças e diferenças entre as características gráficas destes estilos, sua inserção na seqüência sucessória relativa e no espaço, considerando aí suportes típicos, os abrigos e as áreas onde ocorrem em maior freqüência - parece mais produtivo tomar estas expressões como relativas a um único sistema de representações visuais do que como estilos de tradições culturais distintas.

Os resultados da pesquisa levam a defender a necessidade de refletirmos sobre a noção de tradição rupestre que utilizamos no estudo da arte rupestre brasileira. A discussão e elaboração de uma metodologia adequada à pesquisa deste registro arqueológico passa, antes, por uma avaliação da viabilidade conceitual das categorias que aplicamos. No caso brasileiro, onde tradição arqueológica e cultura são noções indissociáveis, precisamos ao menos conhecer os conceitos de cultura subjacentes às categorias classificatórias em uso para que possamos definir em que medida estas categorias são válidas para o contexto arqueológico em análise e que reformulações são possíveis ou necessárias para ajustar as formulações conceituais e a pesquisa empírica.

\section{Tradição e cultura na arqueologia brasileira}

O conceito de tradição arqueológica foi trazido ao Brasil por Betty Meggers e Clifford Evans, coordenadores dos projetos arqueológicos de larga escala da década de 1960, como o PRONAPA (Programa Nacional de Pesquisas Arqueológicas) e o PROPA (Programa de Pesquisas Paleoindígenas). Com o objetivo de fornecer um quadro geral das culturas arqueológicas brasileiras em curto prazo, através 


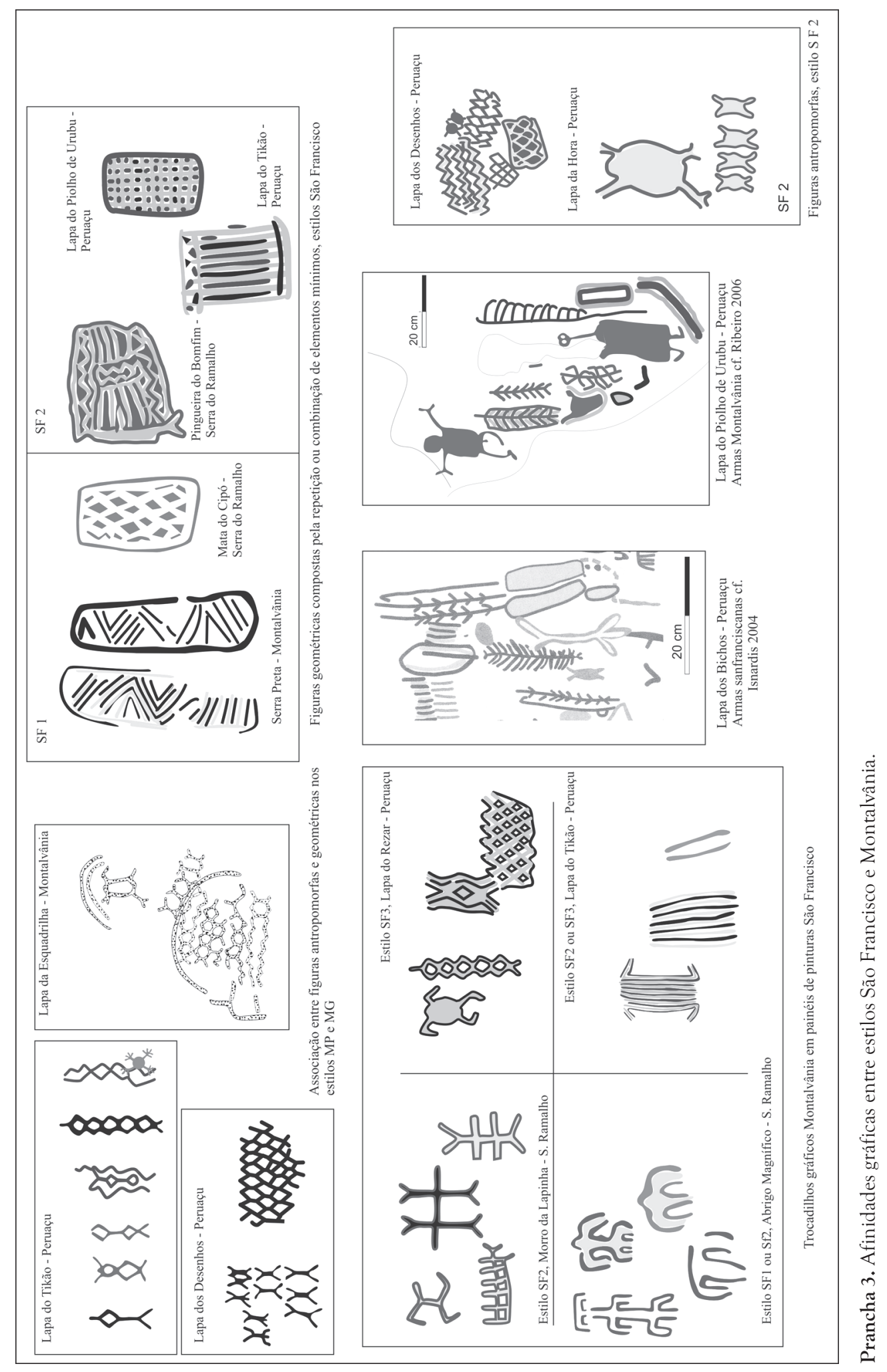


destes programas ${ }^{4}$ foram realizadas prospecções em várias partes do território brasileiro (Prous 1992).

A primeira ordenação da arte rupestre brasileira, seguindo o estabelecimento de cronologias relativas e absolutas e sistematização dos dados empíricos nos conceitos de fase e tradição, foi desenvolvida em 1970 por Valentin Calderón (1970). Entretanto, suas pesquisas com a arte rupestre não tiveram seqüência ou repercussão e, de fato, os primeiros estudos acadêmicos de arte rupestre brasileira foram marcados pela presença estruturalista das Missões Arqueológicas Franco-Brasileiras, que começaram suas atividades na mesma época. Rapidamente, as classificações da arte rupestre em tradições caracterizadas por padrões de similaridade temática e gráfica, seriam adotadas pelos arqueólogos das Missões de Minas Gerais e do Piauí, além de pesquisadores independentes.

As pesquisas da Missão Arqueológica Francesa com a arte rupestre brasileira começaram em 1971 (em Minas Gerais) e tinham por objetivos a determinação estilística cronogeográfica, a caracterização dos temas e composições gráficas, e propostas de interpretação da arte rupestre, através das características próprias dos sítios e através da iconografia e mitologia indígenas (Laming-Emperaire e outros 1974). Paralelamente às detalhadas monografias de sítio, com análises de centenas de metros quadrados de decalques, classificação e contagem de grafismos, iam sendo publicadas apresentações gerais dos abrigos e seus painéis rupestres, com acurado interesse nas relações observadas das figuras entre si, com o sítio e entre este e o meio ambiente (Laming-Emperaire e outros 1974; Guidon 1975; Prous e outros 1977). Procurava-se identificar as regularidades na seleção do espaço gráfico para evidenciar as normas gerais seguidas em cada conjunto e a variação permitida dentro dos padrões. Ainda que houvesse uma abertura nesses trabalhos para

(4) E da adesão a esta agenda metodológica por outros pesquisadores que não participavam do PRONAPA e PROPA. comparações etnográficas, assumia-se que a tentativa de interpretação dos significados deveria ser precedida pela identificação de eventuais estruturas de organização dos grafismos entre si e com a topografia local dos suportes e dos abrigos (Prous 1977: 57). Termos como vocabulário, gramática, sistemas gráficos e regras sintáticas eram recorrentes nestas análises, que partiam de princípios tomados de empréstimo à lingüística. Buscavase, por exemplo, identificar as relações sintáticas entre os grafismos - cor, posição no suporte e/ou no sítio - com o auxílio de gráficos estatísticos e tabelas tipológicas.

As tipologias desempenhavam um papel destacado nos estudos estruturalistas da arte rupestre na medida em que possibilitavam um inventário das figuras disponíveis ao uso e combinação de temas pelos artistas rupestres. De modo geral, os inventários se apresentavam aos pesquisadores simpáticos ao estruturalismo (na arqueologia e na antropologia) como uma importante ferramenta de evidenciação da padronização cultural. O que a arqueologia estruturalista buscava, era, em síntese, reconstruir as etapas sucessivas da evolução das culturas humanas (Emperaire 1973: 129). Como a cultura material expressaria uma ordem simbólica e inconsciente imposta pelos seres humanos a determinadas áreas de suas vidas, inventariando detalhadamente os itens que a compunham e comparando inventários de grupos distintos seria possível identificar tanto a variabilidade cultural, a diversidade aparente, quanto a invariabilidade, estruturas inconscientes e universais do pensamento humano (LéviStrauss 1955). O objeto de estudo da arqueologia estrutural era, portanto, a estrutura de pensamento presente na mente dos seres humanos que produziram o registro arqueológico (Renfrew e Bahn 2000: 446). Tais estruturas seriam como ante-projetos da produção da cultura material. Estariam manifestas nas cadeias operatórias, onde os processos técnicos seriam "organizados em cadeia por uma verdadeira sintaxe que dá às séries operatórias sua fixidez e sutileza" (Leroi-Gourhan 1984: 117); estariam refletidas também nas regras de composição dos sítios rupestres (Leroi-Gourhan 1964). 
Repensando a tradição: a variabilidade estilística na arte rupestre do período intermediário de representações no alto-médio rio São Francisco. Revista do Museu de Arqueologia e Etnologia, São Paulo, 17: 127-147, 2007.

A atuação da escola francesa no Brasil caracterizou-se por trabalhos regionais com inventários de sítios e determinação de seu potencial científico (Laming-Emperaire e outros 1974) e estudo detalhado de poucos sítios, tomados como típicos da unidade maior desconhecida (Barreto 1999). Os sítios escolhidos recebiam escavações de amplas superfícies para reconstrução de solos de ocupação e análises tecno-tipológicas de artefatos, principalmente líticos (idem, ibidem). Aplicada à arte rupestre, esta abordagem resultou em explorações de grandes áreas passíveis de comparação, em sistemáticas e exaustivas reproduções de acervos gráficos e em classificações tipológicas de figuras. Existe uma evidente complementaridade entre os métodos franceses de delimitação espaçotemporal através de seqüências regionais fundadas na reconstrução minuciosa de pisos de ocupação ("reconstruções paleoetnográficas", no dizer de Prous 1992: 16) e o estudo amostral de amplas regiões com sistematização dos dados nas classificações em fases e tradições defendidas pelos membros do PRONAPA. A noção de tradição arqueológica como correspondendo a conjunto de regras culturais cuja aplicação inconsciente orienta a produção da cultura material, condizia com o interesse estruturalista em identificar, através de inventários, os padrões culturais da pré-história. Deste modo, logo após as primeiras pesquisas, os arqueólogos das Missões Franco-brasileiras passaram a adotar tanto intensivas prospecções com levantamentos mais rápidos, definidos por pequenas sondagens, coletas de superfície e reprodução de acervos rupestres, quanto o agrupamento de seus dados em tradições arqueológicas. $^{5}$
A noção desde então vigente de tradição rupestre em muito se sustenta na idéia de que os conjuntos de temas representados com mais freqüência na arte rupestre são manifestações de repertórios culturais, distintos a partir dos repertórios temáticos (Isnardis 2004: 46-47; Pessis e Guidon 2000: 21; Prous 1999a: 255 etc.). Nesta abordagem, a arte rupestre é interpretada como reflexo passivo da orientação cultural de seus autores, onde as mudanças nos padrões de continuidade gráfica são indicativas de mudanças culturais. A noção de tradição rupestre como repertório temático, por sua vez manifestação de repertório cultural, está fortemente enraizada na arqueologia brasileira desde a presença estruturalista nos primórdios da pesquisa sistemática da arte rupestre. No pensamento de Lévi-Strauss, de grande impacto nas análises da arte paleolítica européia desenvolvidas por Leroi-Gourhan (1965) e Laming (1962), a ordem simbólica da cultura pode ser inclusive reconstruída através de inventários. Lévi-Strauss sugeria que inventariando todos os costumes e crenças reais ou possíveis, poder-se-ia elaborar com os mesmos uma tabela periódica (como a dos elementos químicos) agrupando-os em famílias, onde seria preciso apenas reconhecer aqueles efetivamente adotados pelas sociedades. As sociedades humanas, assim como seus indivíduos, não criariam costumes: escolheriam combinações em um repertório ideal passivel de reconstrução (Lévi-Strauss 1955: 203).

A noção de tradição rupestre como repertório temático também encontra suporte em outras correntes antropológicas, não estruturalistas. Ela também pode ser trabalhada segundo a conceituação de Geertz de cultura enquanto sistema simbólico público,

figuras (ver, p. exemplo, Baeta e outros 1992; LamingEmperaire e outros 1974; Ribeiro 1996/97; Vialou 1983-84, 2005, entre outros). O grande investimento de Prous na elaboração das seqüências crono-estilísticas leva alguns arqueólogos (como Dias 2003: 11) a ignorarem a ótica estruturalista que ainda orienta seus trabalhos com arte rupestre, descrevendo-os como redimensionados para as classificações e seqüências estilísticas. 
concebido não como padrões concretos de comportamento, mas como mecanismos de controle para governar o comportamento. Neste sistema simbólico, os significados são objetivos, sociais e públicos, já em uso corrente na comunidade quando nasce o indivíduo e permanecendo após sua morte, com modificações (acréscimos, subtrações e outras alterações parciais) das quais ele participou ou não (Geertz 1989). Lévi-Strauss e Geertz disponibilizam dois conceitos de cultura que permitem discutir e validar a aplicação da noção de tradição rupestre como repertório temático e cultural.

Mas existem outras concepções de cultura que não lidam com a idéia de repertório e que permitem discutir uma noção de tradição rupestre e seu componente normativo sem se restringir aos repertórios temáticos. ${ }^{6}$ Tradição arqueológica também pode ser discutida de acordo com a proposta de Marshall Sahlins, de estrutura na história e enquanto história, em que os conceitos culturais são utilizados ativamente para se engajar no mundo e adquirem novos conteúdos empíricos na ação, alterando a cultura enquanto a reproduzem (Sahlins 1999: 179 e ss). Essa noção de cultura não é marcada pela dicotomia entre continuidade e mudança, ou estrutura e história, mas pela síntese. Ela é interacional e dinâmica, uma "indissolúvel síntese de coisas como passado e presente, sistema e evento, estrutura e história" (Sahlins 1999: 193). A partir dela, os padrões de similaridade podem passar a dividir a atenção com padrões de contrastes, buscando conexões entre eles que sejam significativas de um padrão maior.

Essa formulação de cultura pode ser pensada, por exemplo, na proposta de estilo como qualidade histórica de Ian Hodder (1990). O estilo pelo qual Hodder se interessa não envolve apenas uma prática social, mas todo

(6) Algumas destas concepções, inclusive, não foram gestadas na antropologia, como é o caso da Biologia do Conhecer de Maturana (1997), segundo a qual, a cultura não é algo que se possui, mas uma rede de conversações que define um modo de viver e de agir: um meio interacional do qual se faz parte e que justamente por isto alinha modos de agir (Castro 2003). um modo de vida, no qual produção material, tensões sociais, subsistência, ideologia e crenças religiosas estariam simbolicamente articuladas. Potencialmente holísticas, noções de estilo como as propostas por Hodder (1990), Shanks e Thiley (1990) e outras que têm surgido nas duas últimas décadas, no contexto das discussões sobre os significados da cultura material (Conkey 1987, 1990; Hodder 1982, 1986; Hodder e Hutson 2003 e outros), permitem trabalharmos no sentido de estudos contextualizados da arte rupestre, nos quais ela possa ser mais facilmente associada aos outros itens do registro arqueológico.

\section{Considerações finais}

O estudo da arte rupestre do alto médio São Francisco, aqui apresentado em parte, sugere que as definições da Tradição São Francisco e do Complexo Montalvânia separam, equivocadamente, expressões estilísticas de um mesmo sistema de representações visuais que pode ter se desenvolvido por longo período, hipoteticamente durante boa parte do Holoceno. Abordar estas expressões a partir de dois repertórios temático-culturais distintos mascara a complexidade e intensidade da prática de arte rupestre que pode ser observada no período, ainda sem par nos momentos que a antecedem ou sucedem no contexto gráfico regional.

O componente normativo da noção de estilo aqui utilizada permite trabalhar com a possibilidade de identificar expressões rupestres que se alinhem culturalmente, ${ }^{7}$ todavia acreditando que uma categorização cultural mais ampla (a definição de tradições rupestres) deve ser um eventual resultado da pesquisa e não definição apriorística. A tendência a buscar apenas os padrões de similaridade na arte rupestre, não considerando que as diferenças podem indicar conexão (Sahlins 2004), tem nos levado a uma reconstrução pré-histórica

(7) De acordo com Conkey (1990) qualquer concepção de estilo tem, necessariamente, um caráter normativo. 
em que rígidos repertórios temáticos se sucedem ou permanecem, evocando uma equivalente presença de grupos culturais que eventualmente não encontra correspondente nas camadas arqueológicas estratigráficas.

Para muitos, pode não ser satisfatória essa lógica conceitual que sustenta a noção de tradição rupestre e que permite nortear as análises através de parâmetros fixos e estáticos. O que se defende não é o abandono da noção de tradição arqueológica, mas a necessidade de refletir sobre ela e redefini-la, se for preciso, ampliando nesse exercício as perspectivas de análise e as metodologias de estudo. A questão não é se a arqueologia é capaz de identificar e diferenciar culturas do passado, mas que aspectos de culturas do passado queremos discutir através da arqueologia. Se buscarmos similaridade, encontraremos. Se buscarmos contrastes, encontraremos. Se buscarmos ambos, talvez possamos construir um cenário arqueológico de sociedades mais dinâmicas, onde as repetições e os contrastes constituíssem e fossem constituídos em complexas tradições.

\section{Agradecimentos}

Ao mestre André Prous, interlocutor desde o início; a Pedro Ignácio Schmitz, cujos comentários sempre foram bons para pensar; a Paulo de Blasis, orientador estimulante junto ao MAE/USP e à Fapesp e a esta agência de fomento, cuja bolsa de doutoramento concedida viabilizou o desenvolvimento das pesquisas.

RIBEIRO, L. Rethinking tradition: the rock art stylistic variability in the intermediate period of representations at the high-medium San Francisco River. Revista do Museu de Arqueologia e Etnologia, São Paulo, 17: 127-147, 2007.

Abstract: This article presents the main results of the stylistic-comparative analysis carried through in rock art shelters at the north of the Minas Gerais and southwestern of the Bahia: [1] an hypothetical time-line for the regional rock art occurrences, [2] the characterization of the distribution and use of the space by the styles attributed to the intermediate period occupation of supports, and [3] the characterization of the graphical aspects of these styles, whose appearance and disappearance demarcates the observed ruptures of pattern. Allied to the empirical research results, the final quarrel [4] reflect on the methodological implications of the notion of archaeological tradition in rock art archaeology.

Keywords: Rock art - Central Brazil - Archaeological tradition - Stylistics analysis.

\section{Referências bibliográficas}

BAETA, A.; SILVA, M.; PROUS, A.

1992 Organização do espaço pictural nos sítios rupestres da região de Lagoa Santa-MG.

Anais do $3^{\circ}$ Congresso Associação Brasileira de Estudos Quaternários: 417-430.
BAGGIO FILHO, H.

1991 Breve Notícia sobre a Região Cárstica de Montalvânia/MG. IIIo Congresso da ABEQUA - Publicação Especial no 1. Caderno de Resumos, Belo Horizonte:26. 
BARRETO, C.

1999 Arqueologia Brasileira: uma perspectiva histórica e comparada. Rev. do Museu de Arqueologia e Etnologia. Suplemento 3: 201-212.

BITENCOURT, A.L.; RODET, J.

2002 Evolução morfológica do cânion do Morro Furado no contexto dos calcários carstificados do Grupo Bambuí - Serra do Ramalho, BA/BR. O Carste, 14 (4): 224-243.

CALDERÓN, V.

1970 Nota Prévia sobre três fases da arte rupestre no estado da Bahia. Universitas, 5: 5-17.

CASTRO, V.P.

2003 Para Nadar sem Carregar Repolhos construindo um entendimento biologicamente orientado para as relações entre linguagem, cognição e cultura. Dissertação de mestrado, Belo Horizonte: UFMG/FALE.

CONKEY, M.

1987 New Approches in the Search for meaning? A review of Research in "Paleolithic Art". Journal of Field Archaeology, 14: 413-430.

1990 Experimenting with Style in Archaeology: some historical and theoretical issues. In: Conkey, M.W.; Hastorf, C.A. (Eds.) The uses of style in archaeology. New York, Cambridge University Press: 5-17.

DIAS, A.S.

2003 Sistemas de assentamento e Estilo tecnológico: uma proposta interpretativa para a ocupação pré-coloial do Alto Vale do Rio dos Sinos, Rio Grande do Sul. Tese de doutoramento, São Paulo: FFLCH/USP.

\section{EMPERAIRE, A.}

1973 Approche Méthodique des Cultures Préhistoriques Amérindiennes. In: LeroiGourhan, A. L'Homme, Hier et Aujourd'hui: recueil d'études en hommage à André LeroiGourhan. Paris, Cujas: 671-683.

FOGAÇA, E.

2001 Mãos para o Pensamento: a variabilidade tecnológica de Indústrias líticas de caçadores-coletores holocênicos a partir de um estudo de caso: as camadas VIII e VII da Lapa do Boquete (Minas Gerais, Brasil - 12.000/10.500BP). Tese de doutoramento, Porto Alegre: PUCRS/ $\mathrm{FFCH}$.
GEERTZ, C.

1989[1978] A Interpretação das Culturas. Rio de Janeiro: LTC-Livros técnicos Científicos Editora.

GUIDON, N.

1975 Les Peintures Rupestres de Várzea Grande, Piauí, Brésil. Cahiers d'Archaéologie d'Amerique du Sud. Paris, École de Hautes Étde em Sciences Sociales, n.3.

1981 Tradições e estilos da arte rupestre do sudeste do Piauí. Pré-História Brasileira. Aspectos da arte parietal. Catálogo de Exposição. São Paulo/Belo Horizonte, USP/UFMG: 19-20.

HODDER, I.

1982 Symbols in Action. Cambridge: Cambridge University Press.

1986 Reading the Past - current approaches to interpretation in archaeology. Cambridge [Cambridgeshire], New York: Cambridge University Press.

1990 Style as historical quality. In: Conkey, M.W.; Hastorf, C.A. (Eds.) The uses of style in archaeology. New York, Cambridge University Press: 44-51.

1999 The Archaeological Process. Oxford: Blackwell.

HODDER, I.; HUTSON, S.

2003 Reading the Past - current approaches to interpretation in archaeology. New York: Cambridge University Press, 3th ed.

INGOLD, T.

1995 Building, dwelling, living: how animals and people make themselves at home in the world. In: Strathern, M. (Ed.) Shifiting contexts: Transformations in Anthropological Knowledge. London, Routledge: 57-80.

2000 Perception of the Environment: essays in livelihood, dwelling and skill. London/New York: Routledge.

ISNARDIS, A.

2004 Lapa, Parede, Painel - distribuição das unidades estilísticas de grafismos rupestres do vale do rio Peruaçu e suas relações diacrônicas (Alto-Médio São Francisco, Minas Gerais). Dissertação de mestrado, São Paulo: MAE/USP.

JÁCOME, C.; RIBEIRO, L.

2001 Associações Temáticas Envolvendo Figuras Antropomorfas - análise temática comparativa entre as gravuras e pinturas do complexo Montalvânia. XI Congresso da Sociedade de Arqueologia 
Brasileira. Caderno de Resumos, Rio de Janeiro: 131.

LAMING, A.

1962 La signification de l'art rupestre paléolithique: méthodes et applications. Paris: A. \& J. Picard.

LAMING-EMPERAIRE, A; PROUS, A.; MORAES, A.V. DE; BELTRÃO, M. DA C. DE M.C.

1974 Grottes et abris de la région de Lagoa Santa, Minas Gerais, Brésil. Cahiers d'Archaéologie d'Amerique du Sud. Paris, École de Hautes Étde em Sciences Sociales, n.1.

LEROI-GOURHAN, A

1964 Religions de la Pre-Histoire. Paris: Puf.

1965 Préhistoire de l'Art Occidental. Paris: Éditions d'art L. Mazenod.

1984[1943]Evolução e Técnicas (o Homem e a Matéria). Lisboa: Edições 70.

LÉVI-STRAUSS, C.

1955 Tristes tropiques. Paris: Plon.

MARTIN, G.

1997 Pré-História do Nordeste do Brasil. Recife: Editora Universitária/UFPE (2a. edição).

MATURANA, $\mathrm{H}$.

1997[1988] Ontologia do Conversar. In: MAGRO, C.; GRACIANO, M; VAZ, N. (Orgs.) Ontologia da realidade - Humberto Maturana. Belo Horizonte, Ed. UFMG: 167-181.

PESSIS, A.M.

1989 Apresentação gráfica e apresentação social na tradição Nordeste de pintura rupestre do Brasil. Clio, Série Arqueológica, 5: 11-18.

1999 The Chronology and Evolution of the Prehistoric Rock Paintings in the Serra da Capivara National Park, Piauí, Brazil. In: Strecker, M.; BAHN, P. (Eds.) Dating and the Earliest Known Rock Art. Oxford, Oxbow Books: 41-47.

2003 Imagens da Pé-História - Parque Nacional Serra da Capivara. FUMDAM/ PETROBRÁS.

PESSIS, A.M.; GUIDON, N.

2000[1992] Registros rupestres e caracterização das etnias pré-históricas. In: Vidal, L. (Org.) Grafismo Indígena - estudos de antropologia estética. São Paulo: Studio Nobel, FAPESP.

PROUS, A.

1977 Les Sculptures Zoomorphes du sud Brésilien et de l'Uruguay. Cahiers d'Archaéologie d'Amerique du Sud. Paris, École de Hautes Étde em Sciences Sociales, n.5.
1989 Arte Rupestre Brasileira: Uma Tentativa de Classificação. Revista de Pré-História, 7: 9-33.

1992 Arqueologia Brasileira. Brasília: Editora da UNB.

1996/97 Archéologie du Cours Moyen du Rio São Francisco (Vallées des Rios Peruaçu et Cochá). Arquivos do Museu de História Natural, 17/18: 19-70.

1999a As Categorias Estilísticas nos Estudos da Arte Pré-Histórica: arqueofatos ou realidades? Rev. do Museu de Arqueologia e Etnologia, Suplemento 3: 251-261.

1999b Dating Rock Art in Brazil. In: Strecker, M.; BAHN, P. (Eds.) Dating and the Earliest Known Rock Art. Oxford, Oxbow Books: 29-33.

PROUS, A.; COSTA, F., ALONSO, M.

1996/1997Arqueologia da Lapa do Dragão. Arquivos do Museu de História Natural, 17/18: 139-209.

PROUS, A.; JUNQUEIRA, P.; MALTA, I.

1984 Arqueologia do Alto-Médio São Francisco - região de Januária e Montalvânia. Revista de Arqueologia, 2 (1): 59-72.

PROUS, A.; LANNA, A.L.D; PAULA; F.L. DE.

1980 Estilística e cronologia na arte rupestre de Minas Gerais. Pesquisas, Série Antropologia, 31: 121-146.

PROUS, A; SCHLOBACH, M.

1997 Sepultamentos pré-históricos do Vale do Peruaçu-MG. Rev. do Museu de Arqueologia e Etnologia, 7: 3-21.

PROUS, A.; TEIXEIRA, J.E.; MILLS, C.; COLOMBEL, P.; ANTHONIOZ, S; MONZON,S.

1977 Relatório de Prospecções Realizadas no Município de Montalvânia, MG. Arquivos do Museu de História Natural, 2: 67-118.

RENFREW, C; BAHN, P.

2000[1991] Archaeology: Theories, Methods and Practice. New York: Thames \& Hudson.

RIBEIRO, L.

1996/97 O Acervo Gráfico da Lapa do Gigante. Arquivos do Museu de História Natural, 17/ 18: 331-406.

2003 Organização Temático-Estilística e Distribuição Geográfica dos Registros Rupestres da Serra do Ramalho (SW Da Bahia). XII Congresso da Sociedade de Arqueologia Brasileira - Arqueologias da América Latina. Caderno de Resumos, São Paulo: 166.

2006 Os significados da similaridade e do contraste entre os estilos de arte rupestre 
- um estudo regional das gravuras e pinturas do alto-médio São Francisco. Tese de doutoramento, São Paulo: MAE/USP.

2007 Diálogos internos: relações entre figuras, relações entre estilos São Francisco e Montalvânia. Arquivos do Museu de História Natural, 19/20 (no prelo).

RIBEIRO, L.; ISNARDIS, A.

1996/97 Os Conjuntos Gráficos do Alto - Médio São Francisco (Vale do Peruaçu e Montalvânia) - caracterização e seqüências sucessórias. Arquivos do Museu de História Natural, 17/18: 243-286.

RODET, M.J.

2006 Etude Technologique des Industries lithiques taillées du nord de Minas Gerais, Brésil - depuis le passage Pleistocène/Holocène jusqu'au contact $\mathrm{XVIII}^{\mathrm{ème}}$ siècle. Thèse de doctorat, Paris: Université de Paris X - Nanterre.

RODET, J.; RODET, M. J.; MARIANO, D.; WILLEMS, L.; POUCLET, A.

2005 New approach of the karstic evolution of the canyon of the Peruacu river (Januária - Itacarambi, Minas Gerais, Brazil). 14 $4^{\text {th }}$ UIS Congress. Athens, full paper, CD-Rom.

RUSS, J.; HYMAN, M.; SCHAFFER, H.; ROWE, M.

1990 Radicarbon dating of prehistoric rock paintings by selection oxidation of organic carbon. Nature, 348: 710-71.

SAHLINS, M.

1999[1987] Ilhas de História. Rio de Janeiro: Jorge Zahar Editor.

2004[1993] Esperando Foucault, ainda. São Paulo: Cosacnaify.

SCHMITZ, P.I.; BARBOSA, A., JACOBUS, A.L., RIBEIRO, M.B.

1989 Arqueologia nos cerrados do Brasil central, Serranópolis I. São Leopoldo: Unisinos.

SCHMITZ, P.I.; BARBOSA, A; MIRANDA, A.

1996 Arqueologia nos Cerrados do Brasil Central: sudoeste da Bahia e leste de
Goiás. O Projeto Serra Geral. São

Leopoldo: Unisinos.

SCHMITZ, P.I.; BARBOSA, A; RIBEIRO, M.B; VERARDI,I.

1984 Arte Rupestre no Centro do Brasil - pinturas e gravuras da pré-história de Goiás e oeste da Bahia. São Leopoldo: Unisinos.

SCHMITZ, P.I.; BARBOSA, M.; RIBEIRO, M.B.

1997 As Pinturas do Projeto Serra Geral. São Leopoldo: Unisinos.

SEDA, P.

2003 Picassos da Pedra: antropomorfos e sáurios na arte pré-histórica do norte de Minas Gerais. In: Lemos, M.T.T.B. (Org.) Fronteiras Rompidas: multiculturalidade na América Latina. Rio de Janeiro, UERJ/ UESB: 185-201.

SHANKS, M.; TILLEY, C.

1990 Reconstructing Archaeology: theory and practice. Cambridge: Cambridge University Press.

SILVA, M.M. DE C. E

2002 Os Grafismos Rupestres do Abrigo do Possêidon: desordem e crono-estilística na arte rupestre do Alto-Médio São Francisco (MG). Dissertação de mestrado, Campinas: UNICAMP/ IFCH.

SILVA, M.M. DE C. E; RIBEIRO, L.

1996 Organização Espacial e Correlação Crono-estilística na Arte Rupestre de Montalvânia - MG. In: Kern, A.A. (Org.) Anais da $8^{a}$ Reunião Científica da Sociedade de Arqueologia Brasileira. Porto Alegre: EDIPUCRS, Coleção Arqueologia, 1(2): 103- 118 .

VIALOU, D.

1983/1984 Um nouveau site rupestre au Mato Grosso: l'abri Ferraz Egreja. Revista do Museu Paulista, 29: 39-53.

2005 Representações Rupestres. VilhenaVialou, A. (Org.). Pré-História do Mato Grosso - Santa Elina. São Paulo, EDUSP: 245-254. 